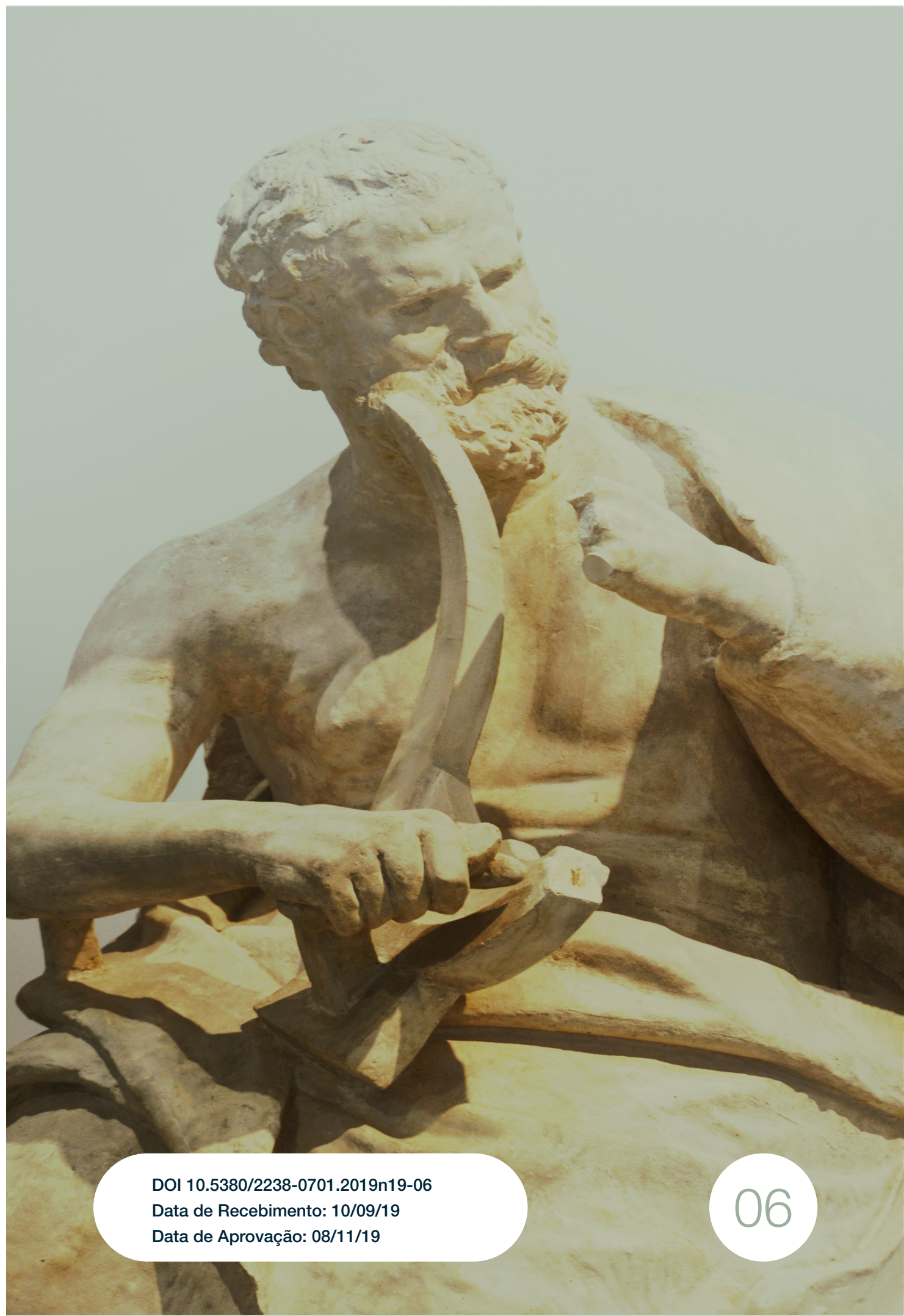


Variações do mito da llíada: Da intercessão divina ao abandono dos mortais 


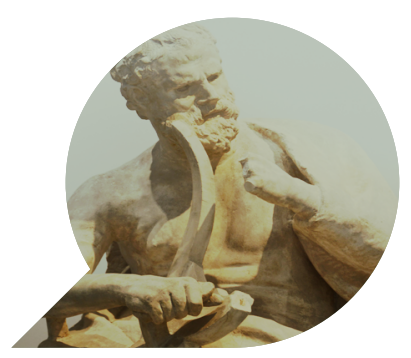

\title{
Variações do mito da llíada: Da intercessão divina ao abandono dos mortais
}

\author{
Iliad Myth variations: From divine intercession to the \\ abandonment of mortals \\ Variaciones del mito de la llíada: de la intercesión divina \\ al abandono de los mortales
}

ANELISE ANGELI DE CARLI ${ }^{1}$

Resumo: Neste artigo, são comparadas duas formas de apresentação do mito da llíada: no romance épico de Homero e no filme Troy. São utilizadas as definições de sagrado e de mito de Mircea Eliade e da derivação do mito em Gilbert Durand para elaborar uma leitura simbólica comparativa. O objetivo é tirar consequências para o sentido do mito através da descrição das cenas no cinema contemporâneo e na literatura arcaica. Conclui-se que o apagamento dos deuses como personagens amplifica a esfera de ação dos homens, ao mesmo tempo em que inviabiliza o ensinamento de modelos exemplares e deixa a humanidade abandonada a seus melhores instintos, os sentimentos nobres e moralmente aceitos em determinado momento histórico.

\footnotetext{
1 Doutoranda do Programa de Pós-Graduação em Comunicação da Universidade Federal do Rio Grande do Sul (PPGCOM/UFRGS), com bolsa CAPES e estágio de pesquisa (CAPES/PDSE) no Institut de Recherches Philosophiques (IRPhiL) da Université Jean Moulin Lyon 3. Membro do Imaginalis - Grupo de Estudos sobre Comunicação e Imaginário, grupo co-fundador do Centre des Recherches Internationales sur l'Imaginaire (CRI2i). É associada e co-fundadora da instituição de ensino sem fins lucrativos Associação de Pesquisas e Práticas em Humanidades (APPH), onde coordena o Grupo de Pesquisa Pensamento por Imagem (GPPimg). E-mail: anelisedecarli@gmail.com
} 
Palavras-chave: Ilíada; Imaginário; Imagem; Mito.

\begin{abstract}
In this paper, two forms of presentation of the lliad Myth are compared: in Homer's epic novel and in the movie Troy. Mircea Eliade's definitions of sacred and myth as well as the mythic derivation on Gilbert Durand are used to elaborate a comparative symbolic reading. The goal to draw consequences for the meaning of myth through the description of scenes in contemporary cinema and archaic literature. It is concluded that the erasure of the gods as characters amplifies the human sphere of action, while makes the teaching of exemplary models unfeasible, leaving humanity abandoned to its best instincts, noble feelings morally accepted at a given historical moment.
\end{abstract}

Keywords: Iliad; Imaginary; Image; Myth.

Resumen: En este artículo, dos formas de presentar el mito de la llíada son comparadas: en la novela épica de Homero y la película Troy. Son utilizadas las definiciones de Mircea Eliade de sagrado y mito, y la derivación del mito de Gilbert Durand para elaborar una lectura simbólica comparativa. El objetivo es sacar consecuencias para el significado del mito a través de la descripción de escenas en el cine contemporáneo y la literatura arcaica. Se deduce al final que la eliminación de los dioses como personajes amplifica la esfera de acción de los hombres, al mismo tiempo que hace inviable la enseñanza de modelos ejemplares y deja la humanidad abandonada a sus mejores instintos, los sentimientos nobles y moralmente aceptados en un momento histórico dado.

Palabras clave: Ilíada; Imaginario, Imagen, Mito.

\title{
Introdução
}

Se for mesmo tarefa dos mitos encarnarem em narrativa a pulsante de simbolismos que responde às perguntas cosmogênicas primordiais da espécie humana (DURAND, 1997), espera-se que seja próprio de- 
les uma plasticidade tal para que continuem cumprindo sua tarefa de maneira eficaz em diferentes momentos da história cultural. Esse é o pressuposto da presente investigação, que pretende descobrir algumas transformações da narrativa mitológica ${ }^{2}$ materializada em dois produtos culturais de diferentes eras.

Apresento a seguir um estudo a respeito das formas de contar o mito da llíada em dois momentos distintos: no poema arcaico de Homero e no filme Troy, dirigido por Wolfgang Peterson e lançado em 2004. Apontando para alterações entre as narrativas, tenho por objetivo compreender que aspectos são retirados e quais são reforçados na narrativa cinematográfica em relação à contação original e o que essas atualizações podem dizer da bacia semântica (DURAND, 1998) - por assim dizer, do estado da arte do imaginário - contemporânea.

O mito é pensado neste texto através dos estudos do simbólico e do imaginário antropológico, principalmente conforme desenvolvidos pela Escola de Grenoble (DURAND, 1997, 1998, 2003). Para compreender o contexto de enunciação de cada uma das duas obras, pontuo algumas breves características da poesia oral arcaica e do funcionamento do mito. Trato esses dados da plataforma de enunciação não somente como características técnicas, mas também fenomênicas, isto é, levando em consideração o que elas provocam de sentido naquilo que enunciam.

\section{Mito, tempo e suas variações: fundamentação teórica}

Palavra desgastada pelo excesso de uso, o mito pode evocar as ideias mais diametralmente opostas. São tantos os significados disponíveis para esse significante - lenda, tradição, falseamento, fantasia, ideologia - que, para continuar a reflexão, preciso reduzir o espectro de noções que vai aqui para circundá-lo. Pensaremos mito junto de Eliade (2011, p. 11), para quem a definição mais ampla seria a mais adequada: o mito é o relato de "[...] um acontecimento ocorrido no tempo primor-

2 Neste artigo, tratamos como "narrativa mitológica" a história contada de um mito que obedece a seu modo de narração próprio (a-lógico). Este termo não deve ser confundido com o que parece significar o termo "narrativa mítica", que estaria mais próximo de narrativa épica, ou seja, o gênero literário que transforma o mito no objeto ou tema de uma narração profana qualquer (ELIADE, 2011). 
dial”. Na concepção do teórico do simbólico e historiador das religiões romeno, o mito, antes de ser uma fantasia sem fundamento pragmático - como hoje o compreendemos no senso comum -, é a explicação de uma realidade tanto quanto o processo pelo qual as coisas passaram a poder existir e ser como são (ELIADE, 2011). É evidente que, como todas as definições, esta também nos cria novos problemas, que são justamente cercar de sentido o que seriam esse tempo e esse primórdio.

A ideia de "tempo primordial" dá a ver que, na experiência reveladora do mito, o tempo do qual se fala não é um tempo absoluto. É dessa maneira que Eliade (2008) relaciona a ideia de mito à ideia de sagrado. $O$ sentimento da sacralidade instaura uma diferente experiência do tempo, em que é possível sempre voltar ao tempo da origem, o tempo da teogonia $^{3}$, o illud tempus. Isso quer dizer que, em vez do tempo cronológico, o tempo do mito é reversível - pelo menos no que diz respeito à experiência. Pode-se sempre voltar ao tempo do mito através do ritual, ou seja, sua reencenação, conforme o que é descrito pelos mitos. O mito, então, é o acontecimento basilar ordenador dos comportamentos, ritos e crenças (ELIADE, 2008). E se o tempo original, dos primórdios, não é um tempo histórico, é mister anunciar que nunca houve testemunha ou comunidade humana que estivesse sequer próxima cronologicamente dele. O primórdio adjetiva esse tempo como um tempo não historicizado.

O mito é também uma narrativa exemplar (ELIADE, 2011). Eliade (2011, p. 22) adiciona o entendimento de que conhecer a origem das coisas nos permite "dominá-las e manipulá-las". Ou seja, o conhecimento mítico não é um conceito recreativo, ele é também um conhecimento útil. E a principal função do mito (ELIADE, 2011, p. 13) é "[...] revelar os modelos exemplares de todos os ritos e atividades humanas significativas". O mito justifica-se como suficientemente verdadeiro não pelo fato de ser comprovável - pois ele não o é -, mas por se referir às coisas reais da experiência humana - à vida, à morte, à natureza, aos sentimentos -, isto é, às coisas que existem e das quais temos conhecimento (ELIADE, 2008). Esse conhecimento não é, de todo, abstrato, mas, pelo contrário, é um conhecimento "vivido" e, mais ainda, "vivido ritualmente" - isto é, repetidamente nas práticas cotidianas da vida, tanto as sagradas quanto

3 O tempo da criação dos próprios deuses, ou da vida, ou do mundo como ele é (ELIADE, 2011; TORRANO, 2011). 
as profanas.

Para entrar nessa noção de mito, é preciso, portanto, abandonar toda a esperança ${ }^{4}$ de encontrar comprovações e causas. Essa noção de tempo ${ }^{5}$, como se percebe, está ligada a uma experiência viva. Cada vez que um ritual - religioso ou profano - reconta um mito, o tempo primordial se torna tempo presente (ELIADE, 2008), tempo experienciado. Seria, portanto, impossível para o mito operar de maneira comprobatória ou reprodutível simplesmente porque não se pode criar o mundo que já existe - e, além disso, porque a cosmogênese não é tarefa dos homens, mas dos "entes sobrenaturais" (ELIADE, 2011, p. 11).

Dessa maneira, fica implícito que as definições acercadas dos estudos do simbólico falam de realidades sem definições precisamente finalizadas, pois a experiência do sagrado se realiza em cada um, em cada sociedade, em cada época, de maneiras particulares. O modo de funcionamento do mito e da explicação que o mito dá ao mundo operam sem a eleição de um significado restrito, sem uma forma de contar única. Pelo contrário, no intuito de continuar funcionando, isto é, ser plástico o suficiente para sobreviver ao longo das variações da história e da cultura, o mito precisa configurar numa espécie de constelação de sentidos, em que um conjunto de significados gravita ao redor do núcleo de sentido central, e o mais adequado a certo momento é o que vem a realizar-se em narrativa (DURAND, 1998).

A hipótese da qual decorre a explicação de Eliade $(2008,2011)$ é a de que alguns grandes temas habitam o pensamento humano das mais primitivas sociedades às mais contemporâneas. Um desses temas recorrentes é a origem. A preocupação com a criação é uma questão existencial, em que um tempo passado dá sentido a um tempo presente e a um tempo futuro. As explicações de origem são inúmeras e suas formas estão relacionadas aos contextos socioculturais de enunciação.

\footnotetext{
4 A citação a Dante não é gratuita. Para nosso pensamento treinado em eleger acontecimentos anteriores e posteriores no tempo - e, assim, causas e consequências - é uma armadilha, um verdadeiro inferno adentrar nessa forma provocadora de pensar sugerida pelos estudiosos do simbolismo. Mas nada que uma pequena precaução às portas da aventura não resolva.

5 Para Torrano (2011), podemos pensar o tempo em outra chave de leitura que não somente a cronológica. O tempo como uma duração quantificável é unicamente uma forma de raciocinar sobre o que seria o tempo. Forma tão naturalizada em nosso tempo a ponto de não mais tomarmo-la como crença (TORRANO, 2011). Para Durand (1998), diante da perecibilidade da matéria (prova da passagem do tempo cronológico), é o sistema imaginário do Homo sapiens que dá acesso ou mesmo dispõe desse tempo reversível.
} 
No entanto, quaisquer que sejam as explicações, essas perguntas nunca serão suficientemente respondidas ou comprovadas, pois correspondem justamente ao mistério tremendo ${ }^{6}$ da existência humana. Na leitura que Barros (2010) faz da tese de Durand (1997) - e que preservo aqui -, é em reposta ao universo de angústias próprio da consciência da morte que a humanidade desenvolve a ferramenta cognitiva do imaginário. Elas não podem ser respondidas no âmbito das comprovações, mas no da experiência: a experiência do mistério, do sagrado, do mito. A forma de respondê-las - isto é, de reagir a essa motivação simbólica, a esse universo angustiante, para mobilizar a proposta de Durand (1997) - se dá através da ativação de outra esfera do pensamento, o mítico, em que as explicações não criam entre os eventos uma relação causa-efeito, mas relações simbólicas, que exigem a implicação do sujeito na ação e, assim, a noção de um tempo reversível. Dadas as possibilidades materiais e as condições culturais de determinada comunidade humana, as maneiras de responder às perguntas primordiais do homem (de onde viemos?; quem somos?; para onde vamos?) sofrem variações. Mas às três perguntas, que são questões relativas ao tempo (o que aconteceu no passado, no presente e no futuro, respectivamente), não caberá outra resposta que não a simbólica, ou seja, uma resposta em forma de mito.

Como falamos anteriormente, se os contextos de enunciação do mito descrevem as partes esquecidas ou enfatizadas do mito canônico, é possível se perguntar que partes do mito sobrevivem no contexto da dessacralização contemporânea próprio das sociedades laicizadas. Na concepção dos estudiosos do imaginário (DURAND, 1997; WUNENBURGER, 1990), essa ferramenta cognitiva não está disponível somente a determinados contextos religiosos ou mesmo para o Homo religiosus (ELIADE, 2011), mas esse sistema imaginário é condição inclusive para o procedimento racional do pensamento lógico-dedutivo, porque, antes de conseguirmos fazer relações causais, é preciso imaginar $n$ relações entre os agentes do fenômeno em questão ${ }^{7}$. Até chegar a uma explicação palatável para o cogito, é preciso muita lapidação, pois a relação entre os fenômenos dada pelo mito, por vezes, é incongruente - se es-

6 Numa referência ao mysterium tremendum (OTTO, 2007), que dá propulsão para o pensamento de Eliade (2008, p. 16), o sentimento de uma esmagadora sensação de poder que nos é totalmente alheia.

7 O mitólogo Grimal (2013, p. 11) afirma que, "quando o raciocínio chega ao limite", a filosofia recorre ao mito "como um modo de conhecimento suscetível de alcançar o incognoscível. 
tivermos pensando a partir de um paradigma em que o encadeamento de acontecimentos deve seguir uma lógica reversível, possível de ser sintetizada em uma regra geral ${ }^{8}$.

Aliado à proposta elidiana, Durand (1997) usa a imagem da constelação para descrever esse processo em que os símbolos se organizam em torno de um tema arquetípico. Isso quer dizer que os temas que constelam ao redor de um núcleo de sentido compartilham de uma mesma origem. Esse núcleo de sentido é a narrativa canônica, as principais lições do mito, tal como dito por Eliade em sua concepção de mito. É a busca por essa origem, por esse mito, que vai ajudar a mostrar as partes encobertas ou esquecidas dessa mesma constelação. A hipótese de Durand (1997) é que, mesmo num contexto agnósticoª , os temas míticos persistem, mesmo que as narrativas reavivem apenas partes de sua narrativa. Algumas partes do mito - que é sempre rico em detalhes - são adaptadas, alteradas, contextualizadas; e é tarefa de uma mitodologia (DURAND, 1996a) procurar a presença das narrativas canônicas, seus temas e variações.

Vale ressaltar que tomar o mito como uma forma de explicação válida não é, de forma alguma, validar moralmente sua forma de explicação ${ }^{10}$. O mito, por vezes, conta histórias trágicas - no sentido de que não apresentam uma solução para o embate - ou mesmo assustadoras - em que o exemplo narrado tem um final horrível e indesejado. A valorização de um mito em certo momento da história não significa que esse

8 Sublinho aqui que os temas arquetípicos não constituem de forma alguma uma estrutura, como aos moldes do estruturalismo. Ao contrário, como bem frisou Durand (1997, p. 63-64) a respeito da diferença - que escreveu essa tese em resposta a Lévi-Strauss -, o sistema imaginário prevê não uma forma em que os conteúdos devem se encaixar para, assim revelar sua funcionalidade e sentido, mas descreve, sim, ao contrário, uma estrutura dinâmica, figurativa, em que o próprio sentido dá a ver a estrutura em funcionamento.

9 As sociedades que mantêm o mito vivo não são somente as "arcaicas" ou não modernas. A encarnação dos temas mitológicos não se limita à época histórica e às disposições técnicas. É em oposição a essa ideia da primeira antropologia que situa o pensamento mítico como uma fase primeira do pensamento cultivado, uma etapa da evolução técnica e científica que Lévi-Strauss (2008) se coloca. Pelo contrário, Lévi-Strauss (2008) afirma que os dois modos do pensamento estão em pé de igualmente em termos de complexidade e validade e que, depois do processo civilizatório moderno do Ocidente, a arte é a principal responsável pela manutenção do pensamento mítico. Não à toa, a narrativa mítica hoje nos chega principalmente (e assim é aceita) como sinônimo de fábula fantástica, sob a forma de entretenimento como o cinema e a literatura de ficção.

10 Já vimos a ascensão do mito de Wotan no contexto do nazismo alemão, como estudou Jung (DURAND, 1996a), tanto quanto hoje vemos a aderência a uma série de estereótipos desumanizadores. 
modo de explicação é moralmente elevado em relação a outro, muito pelo contrário, e está precisamente aí uma das justificativas para o seu estudo. Com isso, passamos para um segundo momento em que nos preocupamos com as capacidades plásticas da narrativa mítica.

\section{Plasticidade do mito: metodologia e simbolismo situado}

Estar na presença das narrativas exemplares nos orienta sobre como melhor agir e pensar, ao lado da nostalgia do tempo perfeito do início. Guardadas suas proporções, hoje nos faz esse favor o cinema, mas na antiga civilização grega "[...] cântaros de vinho, tigelas e recipientes de toda espécie misturavam o mito à vida cotidiana e tornava-os familiares" (GRIMAL, 2013, p. 11). É essa variação da narrativa mítica que Durand (1996a, 1998) descreve no processo da tópica sociocultural. Travestidas de uma série de simbolismos relacionados ao contexto de enunciação, as narrativas míticas sofrem variações ao longo do tempo, reforçando ou apagando arestas de suas incongruências originais. O mito também é vivido nas sociedades modernas e cientificizadas, mas com roupagens que melhor as ornem: são as teorias validadas em cada comunidade de sentido e de prática.

Trato a llíada de Homero aqui como uma forma narrativa de um mito da mesma forma que o filme Troy, cada um sendo produto cultural de um tempo histórico - sendo o último, do nosso. Assim, tanto o poema quanto o filme referem-se a um mito, ou mitos, mas impregnados de diferentes simbolismos, o que guarda relação, como vimos, com as condições sociais, histórias e culturais de enunciação.

Posso continuar o raciocínio na esteira de Grimal (2013), que considera "mito" somente as lendas cosmogônicas, devido ao seu alcance teológico - e poderíamos inferir teleológico. Diferente desses mitos, ele aponta também a existência de ciclos e novelas, que descrevem respectivamente episódios de um personagem (como Hércules) e o desenvolvimento de um tema (com vários ciclos e mitos). O poema llíada é considerado, então, para ele (GRIMAL, 2013, p. 21), uma novela, pois relaciona o ciclo de diferentes personagens (Helena, Aquiles, os Priâmidas) a traços característicos de divindades, citando pedaços do mito "por alusão". 
O mito, como afirma Durand (1997, p. 63) já é um "esboço de racionalização", um primeiro avanço esquemático que, por usar o fio do discurso como estrutura, substitui símbolos por palavras e arquétipos por ideias. No trajeto de sentido (DURAND, 1997), vê-se uma progressiva perda de polissemia dos temas arquetípicos, que se ligam a imagens provenientes das diferentes culturas, de modo a se fazer enunciar/ver, assim dando origem a um simbolismo situado. Como no exemplo de Durand (1997, p. 62), "enquanto o esquema ascensional e o arquétipo do céu permanecem imutáveis, o simbolismo que os demarca transforma-se de escada em flecha voadora, em avião supersônico ou em campeão de salto". A figuração dos mitos em plataformas sensíveis (ou a transformação de símbolos em signos) vai progressivamente descrevendo a constelação simbólica ao redor da qual ele circula, permitindo perceber áreas de concentração ou não de interesse, ou, melhor dizendo, nos permite ver o fortalecimento ou o enfraquecimento de certos aspectos da narrativa mítica - o que Durand (2003) chama, respectivamente, de heresia ou cisma.

Poderíamos afirmar, em linhas gerais, que Troy pertence a um contexto cultural agnóstico. A história do pensamento ocidental tem sido marcada desde o advento político e social da razão aristotélica por uma série de episódios iconoclastas, tais como a escolástica medieval, o cartesianismo, o cientificismo e o historicismo do pensamento ilustrado, das ideologias e das pedagogias (DURAND, 1998; 2008). Não sem resistências, o imaginário passou e passa por esses processos, encontrando maneiras de sobreviver à margem do semantismo estrito de nossa época. A sobrevivência do mito se dá por um processo de redundância e de repetição, em que é preciso que ele encarne tantas vezes quantas sejam necessárias para expor todas as suas incongruências ou dissidências com o pensamento de uma época (DURAND, 1998). Significa dizer que, se nas narrativas míticas arcaicas o símbolo é avizinhado de símbolos imprevistos, a-lógicos, característicos de uma era ágrafa (TORRANO, 2011), nas suas versões contemporâneas, linguajeiras, essas arestas são desbastadas ou se fazem presentes de maneiras não conexas diretamente, mas paralelamente à estrutura principal. É nessa chave que faço uma leitura simbólica - nos termos de uma constelação de imagens que organiza um mito - das duas obras mencionadas.

Para pensar as formas através das quais os mitos se transformam 
em fenômeno social perceptível, Durand (1996a, 1996b, 1998) propõe a ideia de tópica sociocultural. O autor da teoria geral do imaginário se utiliza da tripartição freudiana da psique (id/ego/superego) como uma "referência metafórica" (DURAND, 1996a, p. 134) para um diagrama que representa a movimentação do símbolo na sociedade. A sua tópica descreve os lugares em que os mitos se encontram em relação à sua aceitação na sociedade. Enquanto há uma esfera de identificação (nível actancial) com algo que está no meio dessa tripartição, nos polos habitam as virtudes e utopias valorizadas em certo período do tempo ou os temas arquetípicos desvalorizados nas profundezas da consciência. A movimentação entre os polos permite ascender os mitos ou trechos de mitos que possuem papeis positivos (quer dizer, aceitos), e descender, ou se ocultarem, os que possuem papeis considerados negativos, rechaçados, dissidentes. Essa movimentação de sobe e desce no sistema simbólico dá conta de explicar a variação dos mitos ao longo da história, de modo que alguns temas arquetípicos que encarnam, num primeiro nível de racionalização, nas narrativas míticas, são representados de maneira mais ou menos incompletas. É dessa maneira que olharemos para a llíada e para Troy.

\section{A llíada ontem e hoje: leitura simbólica}

Além de ser característica da formação de sentido do mito, a repetição também é característica da própria poesia oral. Como o registro que restou do tempo arcaico é a versão escrita da llíada, é através dela que se trabalha em retrospectiva, propondo-se explicações a respeito de como deveria acontecer sua narração oral. Segundo Jones (2013), os poetas orais provavelmente decoravam sentenças, frases e cenas semiprontas, mas flexíveis o bastante para encaixar na métrica de sua apresentação. É por isso que, na poesia épica, repetidas vezes lemos que Menelau é dileto de Ares, que o divino Aquiles tem pés velozes ou que Heitor é domador de cavalos.

O uso dos epítetos pode servir para atiçar a memória. Por exemplo, Homero repete que Príamo é dardânio porque sua árvore parental é habitada por Dárdanos em um longínquo tempo. O mesmo vale para o nome da própria cidade de Troia, que poderia ser uma derivação de Trós, 
filho do filho de Dárdano; ou para llo, pai do pai de Príamo, que reina sobre ílion. Outros epítetos podem estar relacionados a relações narrativas. Como Atena Atritona ${ }^{11}$, devido à sua preferência pelos gregos, isto é, os atreus. No entanto, é nesse ponto que gostaria de lembrar que o trabalho de epíteto não é somente um favor à memória dos aedos. $\mathrm{O}$ epíteto é uma forma de funcionamento particular do universo simbólico, pois ele funciona como "arquétipo substantivo" (DURAND, 1997), isto é, como nome que sintetiza uma série de ações, gestos, enfim, de narrativas míticas. Por exemplo, a linhagem familiar de alguma maneira conecta características dos personagens (o que é dito de Dárdano pode também ser dito de Príamo e de Heitor) e também justifica a realeza (se é rei é porque se é descendente de um deus) ${ }^{12}$. Essa lógica epitética coloca em evidência a característica do mito da qual falei anteriormente, a reversibilidade do tempo - pois, assim, é possível inferir que um pai tem tal característica porque seu filho a tem, ou melhor, que um antepassado seja obrigado a realizar uma ação tal como resultado de uma ação que seu descendente faria no futuro. O tema da hamartia ${ }^{13}$ é exemplar para descrever o funcionamento do epíteto no mito.

No entanto, o recurso dos epítetos não é mantido na derivação do mito em filme. Pelo contrário, os personagens são chamados pelos nomes próprios, quase sem ênfase para o seu pertencimento, quer seja familiar, quer seja divino. Essa falta, no entanto, indica também uma presença: a ênfase do indivíduo. Se os vocativos repetem nomes próprios isolados, não está sendo chamada para essa constelação de símbolos uma miríade de noções envoltas naquele personagem. Dá ênfase para a constituição do personagem enquanto sujeito, único, nominado, situado em sua biografia particular.

A isso se soma uma diferença primordial entre as narrativas: no cinema, não vemos os deuses. Há diversos momentos que denunciam o apagamento. Cito, para ilustração, o episódio da morte de Pátroclo, já obliterando as peripécias de Hera no Olimpo. Zeus pede a Apolo que

11 Muito embora na edição de 2013 da llíada pela editora Penguin, diga-se que o nome "atritona" para Atena ainda continue inexplicável.

12 Não à toa, esse mesmo recurso mitológico foi retomado pela monarquia iluminista europeia.

13 No poema, há inclusive uma evocação da noção de hamartia, através da série de corpos roubados. Se os gregos lutam para possuir o corpo de Cebríones, outro filho de Príamo, logo depois o corpo de Pátroclo será desviado da posse dos seus - o que se repete com Heitor. Essa série de vinganças evidencia a forma de funcionamento desse tema, uma espécie de maldição familiar herdada. 
vingue a morte do seu filho Sarpédon (Canto XVI, 668), assassinado por Pátroclo (Canto XVI, 481). O deus maior é quem lança o ímpeto no peito do jovem mirmidão (Canto XVI, 691) e o faz correr atrás da retirada de Heitor até as muralhas de Troia, onde Apolo o espera para a vingança (Canto XVI, 700). Pátroclo se lança em combate em direção aos troianos e Apolo vai em sua direção, tirando-Ihe o elmo protetor. Assim, Euforno consegue golpeá-lo na cabeça (Canto XVI, 812) e, quando o jovem estava em retirada, Heitor pelas costas o atravessa com uma espada no baixo-ventre (Canto XVI, 823). Na disputa pelo corpo, perde-se a armadura de Aquiles, vestida pelo companheiro, que será mais tarde substituída por Atena (Canto XVIII, 204), a pedido de Tétis. Ela, aliás, é importante personagem no poema e substituída por uma versão pacienciosa e amena no filme, que não faz mais do que dar conselhos uma vez ao filho, sem interceder por ele. No cinema, todos esses episódios - que no poema recheiam cinco capítulos - são substituídos por um roubo de armadura e uma morte imprevista, da qual Heitor mostra-se arrependido. Poderia ainda citar rapidamente que Páris é salvo do combate com Menelau não porque Afrodite o resgata e o transporta para a cama de Helena (Canto III, 380), mas porque simplesmente foge para dentro do corpo de soldados troianos.

Os deuses não intercedem nas ações dos personagens, muito menos à revelia dos atos humanos. Eles aparecem somente como citação dos fieis e de forma ecumênica, nunca no campo de batalha onde se dá a maior parte das cenas do poema, mas a menor parte das cenas do filme. As deliberações em relação à guerra parecem ser totalmente humanas, fruto do ímpeto e da coragem próprias dos guerreiros - maneiras, talvez, de encarnar a ideia de divindade no contemporâneo, o sujeito supremo de razão (DURAND, 2008). Se antes o divino era contado como deuses com nomes próprios e isso não assustava os ouvintes dos aedos, hoje a divindade parece ser a exaltação de sentimentos nobres, virtudes superiores que sobrevivem ao momento da mais miserável tragédia. Seria o prenúncio do retorno de uma ética das virtudes aristotélica?

Sobre o fio argumentativo, Jones (2013) afirma que está em funcionamento em Homero um dispositivo chamado "composição anular". Essa forma de compor, em tese, também deveria servir para ajudar a memória dos poetas orais, operando da mesma maneira para o decorar 
de trechos; já aqui, Jones (2013) aponta para a existência de temas que podem se recombinar em diferentes ordens, sem prejuízo do sentido. $O$ exemplo dado por Jones é o episódio do Canto XVII, em que Menelau protege o corpo morto de Pátroclo. A cena começa para que pudessem improvisar em cima de excertos já conhecidos. Isto é, a formação de versos se dá através de uma recombinação de elementos já cantados anteriormente.

É de outra maneira que opera a narrativa cinematográfica. A opção contemporânea foi encadear as ações de maneira, além de cronológica, lógica. Uma guerra é seguida de uma visita diplomática, onde surge um novo conflito, que dá início a uma organização para a guerra etc. O encadeamento dos episódios é como uma escada. No poema, só sabemos que a guerra é causada pelo rapto de Helena muito depois. A narrativa já começa, sem explicação, com uma guerra em curso. 0 encadeamento fímico cria uma experiência de sentido de causa e efeito ao longo de toda a narrativa, diferentemente da versão arcaica, em que, por vezes, não sabemos qual a verdadeira origem do problema narrado - se tem relação com o canto anterior ou o próximo, com os deuses ou com os mortais.

Um rastro desse semantismo restrito, dessa exatidão nos termos, na versão contemporânea, é a relação entre Aquiles e Pátroclo. Para Aquiles, no poema, os bens materiais não são comparáveis à vida (Canto IX, 401). Essa característica é mantida no filme, como no episódio em que ele se indispõe com Agamênon por tomar Briseida de volta. Sua relação com a escrava troiana, no filme, contudo, é amplamente explorada como uma relação apaixonada e intensa. É verdade que também no poema Aquiles afirma tê-la amado (Canto IX, 343), mas esse assunto é tratado a passos largos. A questão de Briseida, no poema, é muito mais enfatizada no quanto ele foi ofendido em sua honra pelo rei dos aqueus ao ter tomados seus espólios de guerra do que por algum coração partido.

É preciso pontuar, ainda, a relação de Aquiles e Pátroclo. A relação, no filme, é de explicitamente de tio e sobrinho. Já no poema é difícil definir: profundos amigos, parentes de criação ou amantes. Essa última versão, inclusive, é a leitura mais aceita da versão arcaica, dado que pesquisas históricas indicam a prática corrente de relações afetivas entre homens velhos e jovens na sociedade grega antiga. Mesmo que em 
todo o poema não haja sequer uma citação sexual a respeito dos dois, há reiteradas declarações do herói afirmando que Pátroclo era seu companheiro mais fiel, seu único igual entre os gregos (Canto XVIII, 80-82). Essa pode ser, simplesmente, uma maneira contemporânea de lermos o afeto entre dois homens. Sem a necessidade de definições precisas, é inquestionável a importância dessa relação, pois é a ira de Aquiles pela morte do companheiro o grande motivo do seu retorno à batalha e de como a llíada encontra seu desfecho - tanto no poema quanto no filme.

Considerando que as festas fúnebres para Heitor são o fechamento do poema e a ira de Aquiles o seu início, o momento em que Príamo implora a devolução do corpo do filho me parece crucial. A cena foi mantida no filme, mas com alterações. Não há intercessão dos deuses para levar o rei troiano em segurança, não há banquete compartilhado entre os inimigos e não há o herói chorando em memória de seus mortos. Uma série de comportamentos aceitos na sociedade arcaica não seriam aceitos hoje $\mathrm{e}^{14}$. Podemos pensar que é devido às práticas sociais, mas também relembraremos que, na sociedade arcaica, o social é também divino à medida que ritualiza o mito - o choro, a ceia e o deslocamento não são somente itens acessórios dessa cena, mas itens que comprovam a presença dos deuses na mediação das relações humanas. Em Homero, a fartura que se compartilha entre guerreiros em ambientes de guerra é narrada lado a lado às ceias no Olimpo. Diria que acontece o mesmo sobre o transbordamento de emoções: no poema, os deuses choram descontrolados, mas um deus contemporâneo - pelo menos os da tradição judaico-cristã - não o faria. Aí se deriva uma espécie de exemplo contemporâneo em que os sentimentos são considerados menos nobres do que a capacidade de discernimento racional.

O mesmo se pode dizer em relação à lírica. Em Homero, os personagens falam como se declamassem poemas com rebuscada retórica. Heróis, guerreiros, tanto quanto os deuses, possuem o mesmo dom da fala e são prolixos. Muitas das vezes, antes de um insulto ou uma discordância, são cantadas e relembradas as virtudes do interlocutor. $\mathrm{Na}$ representação contemporânea, heróis e guerreiros falam muito menos, mais objetivamente e com uma boa dose de ironia e sarcasmo. O guer-

14 Mesmo as festas fúnebres, episódios marcantes em Homero, hoje são replicadas em algumas sociedades, mas de maneira mais sóbria. Não há nenhuma menção a elas no filme. Ao mesmo tempo em que o funeral pode ser repensado de maneira mais séria hoje, pode-se aliar às práticas de ceias e jogos uma recreação alegre e prazerosa. 
reiro provoca seu oponente com insultos, grita ofensas e, por vezes, a palavra humilha-o mais do que o ato violento.

Outro sintoma do desaparecimento dos deuses é a falta de fé talvez outra característica contemporânea que altera as condições de enunciação da narrativa mítica. $O$ temor aos deuses não faz parte do panteão de motivos pelos quais Heitor se entrega à já prevista batalha fatal. Heitor parece no filme, inclusive, em vários momentos, como um troiano infiel aos deuses, sarcástico em relação às leituras dos oráculos, atado às circunstâncias estritamente materiais da cidade. $O$ Heitor do poema llíada, em inúmeros episódios, é chamado de fiel escudeiro de Apolo, reconhecido assim por sua família e sua cidade e principalmente pelos seus epítetos. O ímpeto de lutar do príncipe troiano no cinema não é outro senão o sentimento de dever e de fidelidade com seu pai e sua pátria. Enquanto em todo o enredo do poema Heitor sempre é respeitoso a Príamo e temente a Apolo, no filme, zomba do sacerdote na assembleia e da fé de seu pai e afirma crer somente na força dos homens.

Talvez a ausência das personagens divinas, acompanhada por essa variação das relações familiares, indique o desaparecimento da noção de hamartia. Se, para os antigos, o tronco paternal era o mais valorizado, pois iria cada vez mais além até chegar no criador, ao início do mundo, na versão contemporânea, ele perde espaço para as ligações parentais horizontais e presentes. No cinema, Heitor e Páris têm uma relação muito mais próxima, e o roteiro mostra que Heitor decide encampar a paixão de Páris por Helena, mesmo que essa paixão cause uma guerra. Heitor não despreza Páris por seu papel covarde como o faz fortemente no poema, humilhando-o em público (Canto III, 38). No filme, Heitor compreende o medo do irmão e o mantém a salvo. Quando Páris é levado a salvo da batalha para o leito, no poema, Helena o humilha e o chama de covarde (Canto III, 428), cantando as virtudes do ex-marido. Já no filme, ela é compreensiva, acolhe-o bem e fala que odiava Menelau. Essa relação mais horizontalizada também se dá na versão mais romantizada e menos machista do casal protagonista: no filme, dá-se a entender que houve um envolvimento mútuo entre os dois, quando da visita dos príncipes troianos a Lacedemônia, enquanto no poema, há ênfase somente na ação de Páris, que a teria raptado (Canto III, 443) quase unilateralmente, já que autorizado por Vênus. 


\section{Apagamento das adjacências: do mal ao amor romântico}

De modo geral, há dois aspectos formais totalmente diferentes entre o filme Troy e o poema llíada. Em um primeiro momento, há de se sublinhar o apagamento total dos deuses no filme. Todas as suas peripécias são substituídas por ações do instinto, das emoções e da racionalidade dos homens. Ainda, algo muda na oratória e na demonstração de sentimento dos personagens, e nas celebrações sociais (ceias e fúnebres). Se no poema descobrimos motivos e explicações mais detalhadas de um episódio somente alguns cantos depois, no filme, a sequência de ações é sempre cronológica.

Essas três grandes derivações se relacionam entre si. Nota-se, na forma contemporânea, que há uma sacralização dos sentimentos nobres, como se eles, sim, fossem as únicas certezas possíveis e intuições relevantes, em vez dos oráculos. No lugar dos deuses, colocam-se os sentimentos nobres como modelos exemplares. É enfatizado o respeito à família, por parte dos troianos, o ímpeto libertador de Aquiles que não obedece a um rei injusto como Agamênon, o envolvimento romântico que perdoa todas as ações - como o encampamento que Heitor dá ao irmão, tanto do furto de Helena quanto da fuga do combate, ou mesmo a afeição que Briseida desenvolve por Aquiles. Não se pode deixar de frisar, também, a presença das más condutas, claramente condenadas no filme. Agamênon e a ganância por poder são consecutivas vezes ridicularizadas por Aquiles, tanto quanto essas características do herói são criticadas fortemente por Briseida. Não à toa, Briseida é recompensada no filme com a fuga de Troia. O mesmo acontece com Helena e Páris, a quem as peripécias bondosas e a sinceridade com os sentimentos não foram suficientes para fazê-los merecer o fim trágico original. Esse fim trágico só alcança o rei dos mirmidões, depois de ele ter mostrado todo o mal de que é capaz, na forte cena em que arrasta o corpo de Heitor - possivelmente a única cena quase totalmente preservada do poema no filme.

$\mathrm{Na}$ adaptação cinematográfica, os deuses desapareceram. O seu papel é substituído por motivações humanas, quer sejam sentimentais ou políticas. No poema, as motivações de origem unicamente humanas também existiam, mas os confrontos e preferências dos deuses existiam 
em igual peso, dividindo a responsabilidade pelo curso das coisas. Os homens, no poema, agiam livremente segundo suas deliberações e vontades somente quando da retirada dos deuses do combate. Assim, com o apagamento do papel dos deuses na guerra, há uma consequência e lógica supervalorização do papel dos homens ${ }^{15}$.

Os apagamentos divinos não acontecem sem consequências. $O$ desaparecimento de Tétis deixa à deriva a possibilidade de que seu filho Aquiles também comporte ações do simbolismo da água. Aquiles não chora no filme. No poema, sim, e muito, e a presença continuada de Tétis, titânide do oceano, está lá para possibilitá-lo simbolicamente. Essa ausência divina também acomete Menelau, pois o desaparecimento de Ares não dá ao rei de Esparta a sua condição original de monarca arguto e eloquente. No filme, esse personagem parece bruto e sem nenhuma sofisticação intelectual. Ainda, a retirada de Hera da história inviabiliza a explicação da vitória de Aquiles sobre Heitor, pois é dela a argumentação de que o troiano é um mortal e não deve, portanto, vencer um herói, filho de deuses. A batalha final dos dois no filme parece se dar de igual para igual e não há explicação para sua repentina reviravolta. Por último, é também a ausência de Hera e de Afrodite que dificulta o entendimento do porquê a escolha de Helena ter motivado uma guerra tão grande. No entanto, com a retirada dessas, a justificativa racional da fome por poder de Menelau parece não ser o suficiente para sustentar o argumento fílmico. No lugar da humaníssima competição entre as deusas, resta-nos perceber que, adicionado aos interesses políticos, existe outra divindade escondida, o amor - pois a face escondida e inocente de Vênus parece ter sido a única a sobreviver nos tempos contemporâneos.

\section{REFERÊNCIAS}

BARROS, Ana Taís Martins Portanova. Comunicação e imaginário - uma proposta mitodológica. Intercom - Revista Brasileira de Ciências da Comunicação, São Paulo, v. 33, n. 2, p. 125-143, jul./dez. 2010.

DURAND, Gilbert. A imaginação simbólica. Lisboa: Edições 70, 1995.

DURAND, Gilbert. Le concept de "topique socioculturelle". In: Introduction à la mythodologie. Paris:

15 Aqui literalmente "homens" em vez de "humanos", pois poderíamos ingressar ainda em outro debate a respeito do papel dos homens, dado que as personagens femininas no filme não protagonizam ações de relevância para a trama, em total desacordo com as personagens no poema, quer deusas ou mortais. 
Albin Michel, 1996a, p. 131-156.

DURAND, Gilbert. Campos do imaginário. Lisboa: Instituto Piaget, 1996b.

DURAND, Gilbert. As estruturas antropológicas do imaginário: introdução à arquetipologia geral. São Paulo: Martins Fontes, 1997.

DURAND, Gilbert. O imaginário: ensaio acerca das ciências e da filosofia da imagem. Rio de Janeiro: DIFEL, 1998.

DURAND, Gilbert. Mitos y sociedades: introducción a la mitodología. Buenos Aires: Biblos, 2003.

DURAND, Gilbert. Ciência do homem e tradição: o novo espírito antropológico. São Paulo: TRIOM, 2008.

ELIADE, Mircea. O sagrado e o profano. $2^{\mathrm{a}}$ ed, São Paulo: Martins Fontes, 2008.

ELIADE, Mircea. Mito e realidade. 6 $6^{\mathrm{a}}$ ed, São Paulo: Perspectiva, 2011.

GRIMAL, Pierre. Mitologia grega. Porto Alegre: L\&PM, 2013.

HOMERO. Ilíada. São Paulo: Penguin Classics/Companhia das Letras, 2013.

JONES, Peter. Introdução. In: HOMERO. Ilíada. São Paulo: Penguin Classics/Companhia das Letras, 2013, p. 7-51.

LÉVI-STRAUSS, Claude. O pensamento selvagem. $8^{\mathrm{a}}$ ed, Campinas: Papirus, 2008.

OTTO, Rudolf. O sagrado: aspectos irracionais na noção do divino e sua relação com o racional. São Leopoldo: Sinodal; Petrópolis: Vozes, 2007.

TORRANO, Jaa. A temporalidade da presença absoluta. In: HESÍODO. Teogonia. São Paulo: Iluminuras, 2011, p. 79-80.

WUNENBURGER, Jean-Jacques. A razão contraditória - Ciências e filosofia modernas: o pensamento complexo. Lisboa: Instituto Piaget, 1990.

\section{Referência fílmica}

TROY. Direção de Wolfgang Petersen. Roteiro de David Benioff. EUA/Malta/Reino Unido: Warner Bros. Pictures, 2004 (163 min). 


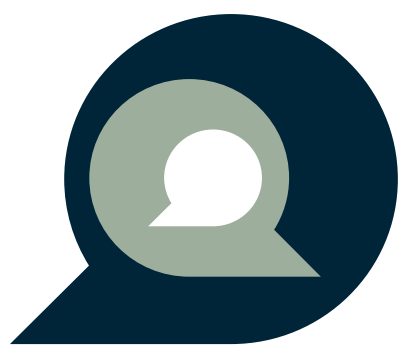

